\title{
Pain and emotion as predictive factors of interoception in fibromyalgia
}

\author{
Céline Borg ${ }^{1-3}$ \\ Florian Chouchou ${ }^{4}$ \\ Jenny Dayot-Gorlero ${ }^{3}$ \\ Perrine Zimmerman' \\ Delphine Maudoux ${ }^{5}$ \\ Bernard Laurent ${ }^{1,4}$ \\ George A Michael ${ }^{3}$
}

'Neurology/Neuropsychology CMRR Unit, Hospital Nord, Saint-Priesten-Jarez, France; ${ }^{2}$ Department of Psychology, University of Lyon, Lyon, France; ${ }^{3}$ Université de Lyon, Université Lyon 2, Laboratory EMC (EA 3082), Bron, France; ${ }^{4}$ Central Integration of Pain (NeuroPain), Inserm UI028, UCB Lyon I, SaintEtienne, France; ${ }^{5}$ EA SNA-EPIS, Department of Clinical and Exercise Physiology, CHU de Saint-Etienne, Saint-Etienne, France
Correspondence: Céline Borg Neurology/Neuropsychology CMRR Unit, Hospital Nord, Avenue Albert Raimond, Saint-Priest-en-Jarez 42270, France Tel +3347782 2888

Email celine.borg@chu-st-etienne.fr
This article was published in the following Dove Press journal: Journal of Pain Research

Introduction: This study investigated interoception in fibromyalgia (FM), a disorder characterized by chronic pain accompanied by mood deregulation. Based on observations on the relationship between somatosensory processing and pain in FM and considering the affective symptoms of this disorder, we tested in FM three dimensions of interoception: interoceptive accuracy (IA), interoceptive awareness (IAW) and interoceptive sensibility (IS).

Materials and methods: Twenty-one female FM patients $\left(\mathrm{M}_{\text {age }}=50.3\right)$ and 21 female matched controls $\left(\mathrm{M}_{\text {age }}=46.3\right)$ completed a heartbeat tracking task as an assessment of IA, rated confidence in their responses as a measure of IAW and completed the Multidimensional Assessment of Interoceptive Awareness as a measure of IS. Furthermore, they completed self-report scales that, according to a principal component analysis, targeted anxiety, emotional consciousness and pain-related affect and reactions.

Results: Multiple regression analyses showed that increased pain-related affect and reactions decrease IA in FM. When the results of each group were examined separately, such effect was found only in FM patients. On its turn, IS was predicted by emotional consciousness and painrelated affect and reactions, but these effects did not differ between FM and controls. Finally, none of the variables we used predicted IAW.

Discussion: Pain-related affect and reactions in FM patients can reduce their interoceptive ability. Our results help to better understand the integration between bodily signals and emotional processing in chronic pain.

Keywords: fibromyalgia, interoception, heartbeat perception, pain, emotion

\section{Introduction}

Fibromyalgia (FM) is a disorder characterized by chronic complaints of spontaneous widespread pain essentially marked by fatigue, sleep disruption and distress. ${ }^{1,2}$ Despite its prevalence, the specific etiology of FM is still unknown. Nevertheless, growing body of research suggests that hypervigilance, defined as high awareness of potentially negative stimuli, seems important in FM and may contribute to sensory overload. ${ }^{3-6}$ Recent research even evidenced abnormally heightened attention to interoceptive signals arising within the body, like spontaneous sensations (SPSs) ${ }^{7}$ and showed that affective aspects of pain modulated this effect. ${ }^{8}$ This suggests that interoception may be amplified in FM (hypervigilance) and modulated by pain.

Interoception is a multidimensional construct ${ }^{9-11}$ and comprises three independent dimensions: accuracy, sensibility and awareness. Interoceptive accuracy (IA) is often measured through the ability to perceive accurately one's own heartbeats..$^{3,12-15}$ 
Even though FM patients are expected to be hypervigilant toward internal signals and more accurate in tracking their own heartbeats, some studies ${ }^{13,16}$ failed to support this hypothesis, since no difference in IA between patients with FM and controls was found. Interestingly though, Duschek et $\mathrm{al}^{17}$ showed that clinical symptoms, including pain, were closely associated with decreased IA in FM. Nevertheless, the literature is quite poor and inconsistent as far as IA in FM is concerned. ${ }^{18}$

On its turn, interoceptive sensibility (IS) is a dispositional tendency to be internally self-focused and interoceptively cognizant. Rost et $\mathrm{l}^{13}$ reported that patients with FM had a heightened focus on bodily sensations, and Borg et $\mathrm{al}^{7}$ confirmed this through the Somatosensory Amplification Scale (SSAS). ${ }^{19}$ However, the same authors, as well as Valenzuela-Moguillansky et al, ${ }^{16}$ did not find any difference between FM and controls using the Multidimensional Assessment of Interoceptive Awareness (MAIA), ${ }^{19}$ another measure of IS assessing attention and emotions related to bodily sensations. These discrepant results may come from different aspects of interoception assessed through these scales. Finally, interoceptive awareness (IAW) is a metacognitive measure of interoception. It can be assessed through the relationship between the accuracy in a heartbeat tracking task and the degree of confidence the participant has in his/her perceived performance in that task. ${ }^{20}$ To our knowledge, this dimension of interoception has never been investigated in FM yet.

One particular aspect of the generalized hypervigilance hypothesis of FM is its relationship with negative affect, anxiety and depression, ${ }^{21}$ which are also related to interoception. Interoception is shaped through higher expression of subjective and physiological indicators of emotional experience and benefits from affect regulation and emotionrelated behaviors ${ }^{22,23}$ as well as from emotional susceptibility. ${ }^{9}$ Nevertheless, the relationship between pain, emotion and interoception ${ }^{24,25}$ is not clear yet. ${ }^{18,24}$ Borg et $\mathrm{al}^{7}$ showed that sensory and affective aspects of pain in FM modulated the perception of bodily sensations, whereas Rost et al ${ }^{13}$ found no relationship between IA and measures of mood and affect. These inconsistencies might be not only due to differences in methodologies but also to the use of different theoretical conceptions of interoception. Therefore, the aim of the current study was twofold: 1) to investigate in a single sample of female FM patients the three dimensions of interoception and 2) to examine the predictive value of affect and mood, hypervigilant self-awareness and pain on interoception.

\section{Materials and methods}

\section{Participants}

The data are presented as mean $\pm \mathrm{SD}$. Twenty-one participants with a diagnosis of FM (all female; mean age (years): 50.3 \pm 8.7 ; age range: $35-62)$ and 21 matched healthy female participants (mean age (years): $46.3 \pm 9.9$; age range: $26-63$ ) were included. The patients met the American College of Rheumatology criteria for FM.,26 Exclusion criteria comprised inflammatory causes of pain, neurological disorders, metabolic abnormalities and severe somatic (eg, cancer) or psychiatric (eg, psychosis) diseases. No patient presented visceral disease. Nevertheless, the presence of comorbid mood disorders, such as anxiety or depression, was accepted. The control participants met the same exclusion criteria as the patients but were also required to be free of pain disorders. There was no difference in age between the two groups $(t(40)=1.4, \mathrm{~ns})$. The mean body mass index was $27.7 \pm 5.2$ $\mathrm{kg} / \mathrm{m}^{2}$ for $\mathrm{FM}$ and $26.0 \pm 5.8 \mathrm{~kg} / \mathrm{m}^{2}$ for the healthy controls $(t(40)=0.96, \mathrm{~ns})$. The mean number of years of education was $12.6 \pm 2.2$ for FM and $14.2 \pm 3.1$ for controls $(t(40)=$ $1.91 ; P=0.07)$. All participants gave their written informed consent for their participation prior to the test. This study was approved by the Ethics Committee/Institutional Review Board of the CHU de Saint-Etienne (no. IORG00077394).

\section{Procedure}

\section{Measures of interoception}

Interoceptive accuracy

A mental heartbeat tracking task was used. Four electrodes were used to record electrocardiogram (ECG) signal: two were placed at the shoulder (one on the left and one on the right) and two on the wrists. ECG signal was recorded, using electrocardiographic MAC5000 $\AA$ acquisition system (Marquette Medical System, Milwaukee, MI, USA), sampled at $500 \mathrm{~Hz}$ and stored in a laptop (inspiron2200®; Dell, Round Rock, TX, USA). The R waves of the ECG were detected by an automatic algorithm based on wavelet transform in a free software HRV analysis. ${ }^{27}$ Artifacts were corrected with a cubic spline interpolation, and each QRS complex was visually validated before being implemented in the analysis. To synchronize testing blocks and ECG, digital triggers were sent to the recording system and stored along with ECG data.

After having placed the ECG electrodes, participants were asked to put a sleep mask. The aim was to reduce any interference from visual input. After a rest period of 5 minutes, the heartbeat tracking task began. Three heartbeat-counting trials were presented, and their duration was 30, 60 and 80 
seconds, respectively. This range was similar to the one used before by our team ${ }^{28}$ and chosen to be larger than in most studies $^{15,29}$ for preventing participants from giving similar responses due to comparable durations of trials. The order was balanced in a Latin-square order across participants. Participants were required to count their heartbeats silently. The beginning and end of each trial were indicated by a tap on the participant's shoulder. Participants were asked not to use any manipulations that might facilitate tracking their heartbeats. At the end of each trial, they had to give verbally the number of heartbeats they had counted. The next trial followed. They were not informed about the duration of each trial. Successive trials were separated by a silent period of 15-40 seconds. The task lasted about 5 minutes. A heartbeat perception score (HBscore) was computed using the following formula: ${ }^{29}$

$$
\text { HBscore }=\frac{1}{3} \sum\left(1-\frac{|\mathrm{rHB}-\mathrm{cHB}|}{\mathrm{rHB}}\right)
$$

where rHB represents the number of heartbeats recorded and cHB the number of heartbeats counted by the participant. The HBscore ranges from 0 to 1 , with higher scores representing more accurate ability to perceive heartbeats. A second accuracy score was computed, and it consisted in the covariance between the recorded and the counted heartbeats. Covariance is a measure of how changes in one variable (here, the number of heartbeats counted by the participants) are associated with changes in a second variable (here, the actual number of heartbeats recorded). Here, it is used as a measure of the degree to which counted and recorded heartbeats are linearly and closely associated.

\section{Interoceptive awareness}

In each trial, participants were required to rate verbally their confidence ( $1=$ not confident at all; $10=$ extremely confident $)$ in their accuracy each time they gave a response. IAW during the heartbeat tracking task was quantified using the covariance between heartbeat accuracy and confidence ratings.

\section{Interoceptive sensibility}

IS was assessed with the French version of the MAIA questionnaire. $^{20,48}$ It consists of 32 items distributed in 8 scales comprising 3-7 items each: Noticing, Not-Distracting, Not-Worrying, Attention Regulation, Emotional Awareness, Self-regulation, Body Listening and Trusting. Participants are requested to score in a $0-5$ scale $(0=$ never, $5=$ always $)$ the frequency with which each one of the listed situations happens. Sample items include "I notice how my body changes when I feel happy/joyful" and "When I feel physical pain, I become upset".

\section{Measure of heart rate at rest}

In addition to the heartbeat tracking task, heart rate at rest was recorded during the intertrial rest periods of 15-40 seconds. Resting heart rate (RHR) was not of central importance here. However, heart rate may have an impact on the main task which was silent heartbeat counting.

\section{Questionnaires assessing mood and affect}

Each participant received a number of questionnaires meant to assess some important characteristics that may influence performance. The aim here was to uncover the way and degree at which these characteristics determine different aspects of interoception.

1. The State-Trait Anxiety Inventory ${ }^{31}$ is a self-completed inventory consisting of two sets of 20 items: one assessing trait anxiety and one assessing state anxiety. All items are rated on a 4-point scale (ie, from "Almost Never" to "Almost Always") for a total score varying from 20 to 80 .

2. A validated French translation of the Beck Depression Inventory (BDI) $)^{32,33}$ assesses the severity of depressive symptoms. The BDI is a 21-question multiple-choice selfreport inventory, with each answer consisting of a scale value ranging from 0 to 3 . Total scores vary between 0 and 63 , and higher scores indicate more severe depressive symptoms.

3. Finally, the Affect Intensity Measure (AIM) ${ }^{34}$ was used. It examines emotional reactions to typical life events. It typically contains 40 items that measure individual differences in affect intensity. Sample items include "When I feel guilt, this emotion is quite strong", "My emotions tend to be more intense than those of most people" and "I can remain calm even on the most trying days" (reverse-scored). A French version of 20 items is available, ${ }^{35}$ each item allowing to measure, on a 6-point scale from Never to Almost Always, how an individual tends to experience emotions.

\section{Questionnaires assessing self-awareness}

1. Somatosensory amplification, referred to as being the tendency to experience somatic sensations as intense, noxious and disturbing, was assessed with the French 
version of the SSAS. ${ }^{19,36}$ The SSAS is a 10-item selfreport questionnaire that requires the respondents to rate, on an ordinal scale of $1-5$, the degree to which each statement is characteristic of them in general. A higher total score indicates greater symptom amplification.

2. Self-awareness was assessed through the French version of the Self-Consciousness Scale (SCS). ${ }^{37,38}$ It is a 23 -item self-report questionnaire using 5-point ratings $(0=$ extremely uncharacteristic to $4=$ extremely characteristic) divided into three subscales: private self-consciousness, public self-consciousness and social anxiety. Sample items include "It takes me time to get over my shyness in new situations", "I get embarrassed very easily" and "I generally pay attention to my inner feelings".

\section{Questionnaires assessing pain and pain catastrophizing}

1. The Visual Analogue Scale (VAS) was used to measure the level of pain and consists of a $10-\mathrm{cm}$ straight horizontal line with the end points defining extreme limits such as "no pain at all" and "pain as bad as it could be". The patient is asked to mark his/her pain level on the line between the two end points. The distance in centimeters between "no pain at all" and the mark then defines the subject's pain.

2. A French version of the Pain Catastrophizing Scale $(\mathrm{PCS})^{39,40}$ was also used in this study. The PCS is a 13 -item self-report questionnaire divided in three subgroups: rumination, exaggeration and vulnerability. Participants had to assess their personal experience with a 5-point scoring from 0 to 4 . Final scores vary from 0 to 52 .

3. The Questionnaire Douleur Saint-Antoine (QDSA) ${ }^{41}$ is a French adaptation of the McGill Pain Questionnaire. It was used to evaluate more qualitatively the pain, pain perception and sensory and affective aspects of pain. It includes 61 descriptors divided into 16 subclasses: nine sensory, seven affective and one evaluative. This questionnaire makes it possible to specify a notion of intensity and appreciates the experience of the pain. For each word group category, the patient surrounds the most representative word of his/her pain and then rates it from 0 to 4 . A total score can be calculated by summing the numbers of each word.

\section{Measure of auditory selective attention}

It has already been demonstrated that selective attention is also relevant for interoception, ${ }^{11}$ even though they are two different functions. ${ }^{42}$ Therefore, in order to disentangle the contribution of attention from that of interoception, a task of auditory selective attention was also completed by each participant. It consisted in three digitalized auditory files of 30,60 and 80 seconds containing, respectively, sequences of 36,71 and 95 auditory stimuli of $21 \mathrm{~dB}$ (thus, 71-72 stimuli per minute) similar to heartbeats. The duration of each beat was $740 \mathrm{~ms}$. In order to increase the difficulty of the task, the interbeat interval (from the end of one beat to the beginning of the next) varied unpredictably from 10 to $575 \mathrm{~ms}$, and a continuous background Brownian noise (strong in longer wavelengths) of $25 \mathrm{~dB}$ was added. Participants had to count beats silently. At the end of each sequence, they were asked to report verbally the number of beats they had counted. The following trial then began. The duration of each trial was not given to participants in order to avoid any response strategies. The order of the sequence was balanced in a Latin-square order across participants.

\section{Statistics}

The simple comparison between FM patients and controls for each one of the collected variables was achieved through the Welch's adaptation of the $t$-test for independent samples ${ }^{43}$ in order to account for any inequality of variance between the groups. The analysis of the determinants of interoception was done through two separate steps. During a first step, a principal component analysis (PCA) with Varimax rotation was used to identify and compute composite scores for the factors underlying the nine scales completed by participants. During a second step, the predictive value of the three factors identified through the PCA and of selective attention on variables representing interoception was assessed through multiple regressions. Being important for interoception, age, body mass index and $\mathrm{RHR}^{44}$ were also entered as predictors. Naturally, since differences between FM patients and controls were at the center of the present investigation, group was also entered as a predictive variable (controls were coded as 1 and FM patients as 2, in a way that a positive predictive relation would intimate an effect in the FM group).

\section{Results}

The results are presented in Table 1, and except when noted differently, are presented in the text as mean \pm SD. Data in the MAIA scale were missing for two controls and three patients.

\section{Resting heart rate}

No difference was found in the RHR between the two groups $(\mathrm{FM}=81.7 \pm 9.2 \mathrm{bpm} ;$ controls $=79.3 \pm 9.7 \mathrm{bpm} ; t(40)=$ 0.81 , ns). 
Table I General data (mean and SD) from the present study

\begin{tabular}{|c|c|c|c|c|c|}
\hline \multirow[t]{2}{*}{ Data } & \multirow[t]{2}{*}{ Controls } & \multirow[t]{2}{*}{ Fibromyalgia } & \multicolumn{2}{|c|}{ Welch's } & \multirow[t]{2}{*}{ Cohen's d } \\
\hline & & & $t$-value & $P$-value & \\
\hline \multicolumn{6}{|l|}{ Demographics } \\
\hline Age, years & $46.3(9.9)$ & $50.3(8.7)$ & 1.40 & 0.17 & 0.43 \\
\hline Years of education & $14.2(3.1)$ & $12.6(2.2)$ & 1.91 & 0.07 & 0.59 \\
\hline \multicolumn{6}{|l|}{ Physiology } \\
\hline Body mass index, $\mathrm{kg} / \mathrm{m}^{2}$ & $26.0(5.8)$ & $27.7(5.2)$ & 0.96 & 0.34 & 0.59 \\
\hline Resting heart rate, bpm & $79.3(9.7)$ & $81.7(9.2)$ & 0.81 & 0.42 & 0.25 \\
\hline \multicolumn{6}{|l|}{ Interoception } \\
\hline HBscore & $0.39(0.32)$ & $0.47(0.3 \mathrm{I})$ & 0.89 & 0.37 & 0.28 \\
\hline Recording/response covariance & $263(293)$ & $372(287)$ & 1.21 & 0.23 & 0.28 \\
\hline Confidence/accuracy covariance & $0.04(0.3)$ & $-0.01(0.1)$ & 0.66 & 0.51 & 0.20 \\
\hline \multicolumn{6}{|l|}{ Sensibility (MAIA scale) } \\
\hline Noticing & $13.05(4.01)$ & $14.83(3.17)$ & -1.5 & 0.14 & 0.49 \\
\hline Not-Distracting & $5.9(3.38)$ & $6.33(3.36)$ & -0.3 & 0.70 & 0.13 \\
\hline Not-Worrying & $9.74(3.78)$ & $8.39(4.26)$ & 1.01 & 0.32 & 0.34 \\
\hline Attention Regulation & $18.68(7.82)$ & $17.44(6.47)$ & 0.52 & 0.60 & 0.17 \\
\hline Emotional Awareness & $13.9(4.4 I)$ & $15.39(3.45)$ & -1.1 & 0.26 & 0.38 \\
\hline Self-regulation & $9.05(4.77)$ & $7.83(3.79)$ & 0.86 & 0.39 & 0.28 \\
\hline Body Listening & $9.42(6.16)$ & $8.83(4.2)$ & 0.34 & 0.74 & 0.11 \\
\hline Trusting & $10.21(4.01)$ & $6.72(3.29)$ & 2.90 & $0.006 *$ & 0.95 \\
\hline Total MAIA & $89.9(24.3)$ & $85.7(15.6)$ & 0.61 & 0.54 & 0.20 \\
\hline \multicolumn{6}{|l|}{ Mood and affect } \\
\hline State Anxiety & $43.0(10.5)$ & $46.4(7.3)$ & 1.20 & 0.24 & 0.37 \\
\hline Trait Anxiety & $45.6(9.0)$ & $46.8(5.3)$ & 0.54 & 0.59 & 0.17 \\
\hline $\mathrm{BDI}$ & $3.09(2.7)$ & $9.85(5.5)$ & 4.97 & $0.001 *$ & 1.54 \\
\hline AIM & $76.9(13.9)$ & $81.2(12.3)$ & 1.06 & 0.29 & 0.33 \\
\hline \multicolumn{6}{|l|}{ Self-awareness } \\
\hline SSAS & $27.4(5.6)$ & $33.1(4.1)$ & 3.77 & $0.001 *$ & 1.17 \\
\hline SCS & $52.7(11.2)$ & $50.5(12.5)$ & 0.58 & 0.56 & 0.18 \\
\hline \multicolumn{6}{|l|}{ Pain and catastrophizing } \\
\hline VAS pain & $0.94(2.0)$ & $4.26(1.9)$ & 5.43 & $0.001 *$ & 1.68 \\
\hline PCS & $15.5(8.5)$ & $30.7(9.6)$ & 5.40 & $0.001 *$ & 1.67 \\
\hline QDSA & $38.9(20.2)$ & $105.3(40.8)$ & 6.67 & $0.001 *$ & 2.06 \\
\hline \multicolumn{6}{|l|}{ Auditory attention } \\
\hline Accuracy & $0.89(0.08)$ & $0.85(0.09)$ & 1.34 & 0.19 & 0.33 \\
\hline Stimulus/response covariance & $628(89)$ & $656(79)$ & 1.07 & 0.29 & 0.42 \\
\hline
\end{tabular}

Note: *Significant difference between FM patients and controls; bicaudal probability.

Abbreviations: Hbscore, heartbeat perception score; MAIA, Multidimensional Assessment of Interoceptive Awareness; BDI, Beck Depression Inventory; AIM, Affect Intensity Measure; SSAS, Somatosensory Amplification Scale; SCS, Self-Consciousness Scale; VAS, Visual Analogue Scale; PCS, Pain Catastrophizing Scale; QDSA, Questionnaire Douleur Saint-Antoine; FM, fibromyalgia.

\section{Interoception}

First, correlational analyses (Table 2) showed an expected strong positive correlation between the HBscore and the recording/response covariance $(r(40)=0.775, P<0.001)$. This suggests that the two scores measure much of the same thing, that is, accuracy of heartbeat perception. No link between IAW (the covariance between the HBscore and confidence ratings) and IS (the MAIA subscales and total) was found. A positive correlation was found between the recording/response covariance (an IA measure) and the NotWorrying subscale of the MAIA $(r(35)=0.387, P<0.02)$.

\section{Accuracy}

The range of the heartbeat perception scores was $0.0-0.97$, with a mean of $0.43 \pm 0.32$. This is within the range of the results reported previously in the literature (eg, mean $=0.57$, range $=$ $0.0-1.0,{ }^{24}$ mean $=0.65^{42}$ ). The internal consistency was excellent as suggested through the high Cronbach's alpha coefficient (0.94). No difference was found in the HBscore between the two groups $(\mathrm{FM}=0.47 \pm 0.31$; controls $=0.39 \pm 0.32 ; t(40)=$ $0.96, \mathrm{~ns})$. Furthermore, no difference was found in the recorded/ counted heartbeats covariance between the two groups (FM = $372 \pm 287$; controls $=263 \pm 293 ; t(40)=1.21, n s)$. 


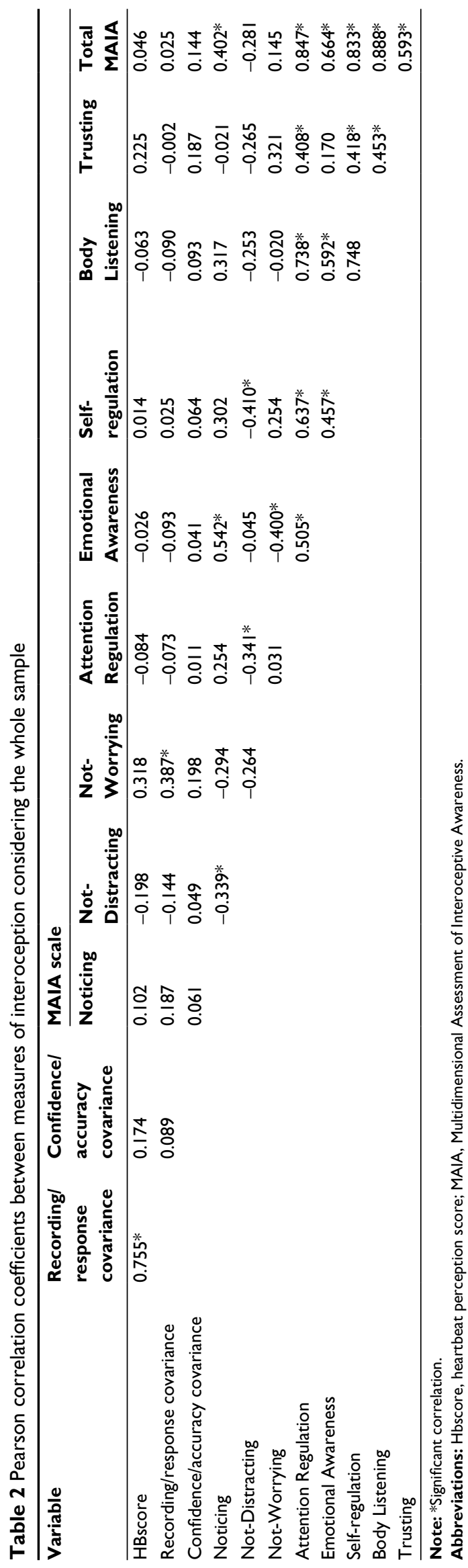

\section{Awareness}

Mean confidence ratings did not differ between patients with FM (4.44 \pm 1.6$)$ and controls $(3.86 \pm 2.1 ; t(40)=0.99, \mathrm{~ns})$. IAW expressed as the covariance between the HBscore and confidence ratings did not differ between the two groups $(\mathrm{FM}=-0.01 \pm 0.1 ;$ controls $=0.04 \pm 0.3 ; t(40)=0.66, \mathrm{~ns})$.

\section{Sensibility}

Patients with FM scored lower in the Trusting subscale of the MAIA (FM $=6.72 \pm 3.29$; controls $=10.21 \pm 4.01 ; t(35)$ $=2.90, P<0.006$, Cohen's $d=0.95$ ). No other differences were found, and no difference was found either between the two groups in the total score of the MAIA scale $(\mathrm{FM}=85.7$ \pm 15.6 ; controls $=89.9 \pm 24.3 ; t(35)=0.61, \mathrm{~ns})$.

\section{Questionnaires of mood and affect}

The scores in the BDI were higher for FM patients $(9.85 \pm$ 5.5) than controls $(3.09 \pm 2.7 ; t(40)=4.97, P<0.001$, Cohen's $d=1.54)$. No differences were found between the two groups in the State $(\mathrm{FM}=46.4 \pm 7.3$; controls $=43.0 \pm 10.5$; $t(40)$ $=1.20, \mathrm{~ns})$ and Trait Anxiety $(\mathrm{FM}=46.8 \pm 5.3$; controls $=$ $45.6 \pm 9.0 ; t(40)=0.54, \mathrm{~ns})$ questionnaires nor in the AIM $(\mathrm{FM}=81.2 \pm 12.3$; controls $=76.9 \pm 13.9 ; t(40)=1.06, \mathrm{~ns})$.

\section{Questionnaires of self-awareness}

The scores in the SSAS were higher for FM patients (33.1 $\pm 5.5)$ than controls $(27.4 \pm 5.6 ; t(40)=3.77, P<0.001$, Cohen's $d=1.17$ ), but no difference was found between the two groups in SCS $(\mathrm{FM}=50.5 \pm 12.5$; controls $=52.7 \pm$ $11.2 ; t(40)=0.58, \mathrm{~ns})$.

\section{Questionnaires of pain and pain catastrophizing}

Reliable differences between FM patients and controls were found in the pain VAS $(\mathrm{FM}=4.26 \pm 1.9$; controls $=0.94 \pm$ $2.0 ; t(40)=5.43, P<0.001$, Cohen's $d=1.68$ ), the PCS (FM $=30.7 \pm 9.6$; controls $=15.5 \pm 8.5 ; t(40)=5.40, P<0.001$, Cohen's $d=1.67$ ) and the QDSA (FM $=105.3 \pm 40.8$; controls $=38.9 \pm 20.2 ; t(40)=6.67, P<0.001$, Cohen's $d=2.06$ ).

\section{Auditory selective attention}

The same equation as for the HBscore was used here in order to compute accuracy. No difference was found between the two groups in the accuracy with which auditory signals were counted $(\mathrm{FM}=0.85 \pm 0.09$; controls $=0.89 \pm 0.08 ; t(40)=$ $1.34, \mathrm{~ns})$. The covariance between the number of presented targets and the number of counted targets was also computed. It correlated with the mean accuracy in the same task 
$(r(40)=0.51, P<0.001)$. Once again, no difference was found between FM patients $(656 \pm 79)$ and controls $(628 \pm$ $89 ; t(40)=1.07, \mathrm{~ns})$.

\section{Correlation analyses}

Correlation analyses were carried out in order to unravel isolated linear links between IA, IAW and IS on one hand and the nine scales assessing mood and affect, self-awareness and pain and catastrophizing on the other hand (Table 3 ). IA, as assessed through the HBscore and the recording/ response covariance, did not correlate with any of the scales. IAW, as assessed by the confidence/accuracy covariance, correlated negatively with pain expressed at time of testing $(r(40)=-0.335, P<0.03)$. Finally, IS, as assessed through the subscales of the MAIA, correlated with several other instruments. Noticing correlated with the AIM $(r(35)=$ $0.446, P<0.006)$ and the QDSA $(r(35)=0.399, P<0.02)$. Not-Worrying correlated negatively with the BDI $(r(35)=$ $-0.517, P<0.001)$, the SSAS $(r(35)=-0.355, P<0.03)$, the SCS $(r(35)=-0.518, P<0.001)$ and the PCS $(r(35)=$ $-0.468, P<0.004)$. Emotional Awareness correlated with the AIM $(r(35)=0.440, P<0.007)$, the SSAS $(r(35)=0.389$, $P<0.02)$, the SCS $(r(35)=0.494, P<0.002)$ and the PCS $(r(35)=0.344, P<0.04)$. Body Listening correlated with the SSAS $(r(35)=0.390, P<0.02)$ and the SCS $(r(35)=0.421$, $P<0.01)$. Trusting correlated negatively with the BDI $(r(35)$ $=-0.393, P<0.02)$, the PCS $(r(35)=-0.461, P<0.004)$ and the QDSA $(r(35)=-0.468, P<0.004)$. Finally, no correlations were found as far as the Not-Distracting and the
Attention Regulation subscales were concerned. The total score of MAIA did not correlate with the other self-reported instruments, and this can be easily explained by the fact that some of its subscales correlated positively while others negatively with those instruments, mutually neutralizing their effects.

\section{Determinants of interoception}

In the PCA (Table 4), initial eigenvalues indicated that three factors explained $19.5 \%, 11.7 \%$ and $40.7 \%$ of the variance, respectively, and all scales met a minimum criterion of having a primary factor loading of 0.40 or above. The first factor included the State and the Trait Anxiety scales and was labeled "Anxiety". The second factor included the SCS and the AIM and was labeled "emotional consciousness". Finally, the third factor included the BDI, the SSAS, the PCS, the QDSA and the VAS measuring pain at the moment of testing. Therefore, this factor was labeled "pain-related affect and reactions".

The results of multiple regressions assessing the determinants of interoception are presented in Tables 5 and 6 and are presented in the text as $\beta$ coefficients \pm standard error of the mean.

\section{Accuracy}

Two variables predicted HBscore $\left(R^{2}=0.25, R_{\text {Adj }}^{2}=0.062\right.$; Table 5). It was positively predicted by group $(\beta=0.759 \pm$ $0.29, P<0.014)$ and negatively by pain-related affect and reactions $(\beta=-0.627 \pm 0.30, P<0.025)$. This result intimates

Table 3 Pearson correlation coefficients between measures of interoception and self-reported instruments assessing mood and affect, self-awareness, pain and catastrophizing. The whole sample is considered.

\begin{tabular}{|c|c|c|c|c|c|c|c|c|c|}
\hline \multirow[t]{2}{*}{ Variable } & \multicolumn{4}{|c|}{ Mood and affect } & \multicolumn{2}{|c|}{ Self-awareness } & \multicolumn{3}{|c|}{ Pain and catastrophizing } \\
\hline & $\begin{array}{l}\text { State } \\
\text { Anxiety }\end{array}$ & $\begin{array}{l}\text { Trait } \\
\text { Anxiety }\end{array}$ & BDI & AIM & SSAS & SCS & $\begin{array}{l}\text { VAS } \\
\text { pain }\end{array}$ & PCS & QDSA \\
\hline HBscore & 0.073 & 0.153 & -0.138 & 0.246 & -0.136 & -0.213 & $0.07 \mathrm{I}$ & -0.139 & 0.078 \\
\hline Recording/response covariance & 0.091 & 0.056 & -0.115 & 0.108 & -0.127 & -0.265 & -0.024 & -0.170 & 0.063 \\
\hline Confidence/accuracy covariance & -0.029 & -0.120 & -0.092 & 0.012 & -0.160 & 0.146 & $-0.335^{*}$ & -0.074 & -0.108 \\
\hline \multicolumn{10}{|l|}{ MAIA scale } \\
\hline Noticing & 0.283 & 0.175 & 0.223 & $0.446 *$ & 0.273 & 0.334 & 0.116 & 0.273 & $0.399 *$ \\
\hline Not-Distracting & -0.039 & -0.054 & 0.280 & -0.069 & -0.016 & 0.254 & -0.120 & 0.102 & 0.147 \\
\hline Not-Worrying & -0.147 & -0.033 & $-0.517^{*}$ & -0.290 & $-0.355^{*}$ & $-0.518^{*}$ & -0.238 & $-0.468 *$ & -0.297 \\
\hline Attention Regulation & 0.070 & 0.032 & -0.104 & 0.216 & 0.230 & 0.214 & 0.017 & -0.123 & 0.036 \\
\hline Emotional Awareness & 0.072 & 0.019 & 0.240 & $0.440 *$ & $0.389 *$ & $0.494^{*}$ & 0.160 & $0.344 *$ & 0.291 \\
\hline Self-regulation & 0.069 & -0.055 & -0.203 & 0.174 & 0.219 & 0.194 & -0.078 & -0.231 & -0.044 \\
\hline Body Listening & 0.152 & 0.002 & 0.061 & 0.227 & $0.390 *$ & $0.42 I^{*}$ & 0.055 & -0.031 & 0.125 \\
\hline Trusting & -0.104 & -0.022 & $-0.393 *$ & 0.077 & -0.086 & 0.000 & -0.154 & $-0.46 I^{*}$ & $-0.468 *$ \\
\hline Total MAIA & 0.087 & 0.016 & -0.110 & 0.283 & 0.262 & 0.319 & $-0.04 I$ & -0.150 & 0.037 \\
\hline
\end{tabular}

Note: *Significant correlation.

Abbreviations: BDI, Beck Depression Inventory; AIM, Affect Intensity Measure; SSAS, Somatosensory Amplification Scale; SCS, Self-Consciousness Scale; VAS, Visual Analogue Scale; PCS, Pain Catastrophizing Scale; QDSA, Questionnaire Douleur Saint-Antoine; MAIA, Multidimensional Assessment of Interoceptive Awareness. 
that the higher the pain-related affect and reactions in FM patients, the lower the IA. A further trend-predictive effect of body mass index was found $(\beta=0.352 \pm 0.19, P<0.075)$. In order to better understand these findings, the same regression analyses were carried out for each group separately. None of the independent variables predicted the results of the controls. However, the HBscore of FM patients was negatively predicted by pain-related affect and reactions $(\beta=-0.668$ $\pm 0.23, P<0.015)$ and positively predicted by emotional consciousness $(\beta=0.522 \pm 0.22, P<0.035)$ and body mass index $(\beta=0.231 \pm 0.19, P<0.016)$.

As far as the recording/response covariance is concerned, it was also predicted by the same variables $\left(R^{2}=0.35, R_{\text {Adj }}^{2}=\right.$

Table 4 Factor loadings associated with a principal component analysis carried out on the self-reported measures. Three components were identified.

\begin{tabular}{llll}
\hline $\begin{array}{l}\text { Questionnairel } \\
\text { scale }\end{array}$ & Anxiety & $\begin{array}{l}\text { Emotional } \\
\text { consciousness }\end{array}$ & $\begin{array}{l}\text { Pain-related } \\
\text { affect and } \\
\text { reactions }\end{array}$ \\
\hline State Anxiety & 0.907 & & \\
Trait Anxiety & 0.942 & & \\
SCS & & 0.954 & \\
AIM & & 0.463 & 0.763 \\
BDI & & & 0.744 \\
SSAS & & & 0.820 \\
PCS-CF & & & 0.803 \\
QDSA & & 11.7 & 0.825 \\
VAS pain & & 40.7 \\
\% Variance explained & 19.5 & 11 & \\
\hline
\end{tabular}

Abbreviations: SCS, Self-Consciousness Scale; AIM, Affect Intensity Measure; BDI, Beck Depression Inventory; SSAS, Somatosensory Amplification Scale; PCS-CF, Pain Catastrophizing Scale - French Version; QDSA, Questionnaire Douleur SaintAntoine; VAS, Visual Analogue Scale.
$0.196)$ : positively by group $(\beta=0.825 \pm 0.27, P<0.004)$ and negatively by pain-related affect and reactions $(\beta=-0.674 \pm$ $0.28, P<0.02)$. In order to better understand these findings, the same regression analyses were carried out for each group separately. None of the independent variables predicted the results of the controls. However, the recording/response covariance of FM patients was negatively predicted by painrelated affect and reactions $(\beta=-0.869 \pm 0.37, P<0.033)$. In agreement with the previous result, this one suggests that the higher the pain-related affect and reactions in FM patients, the lower the IA.

\section{Awareness}

The confidence/accuracy covariance was not predicted by any variable (Table 5).

\section{Sensibility}

The total score in the MAIA scale was positively predicted by emotional consciousness $(\beta=0.645 \pm 0.21, P<0.005$; $\left.R^{2}=0.35, R_{\text {Adj }}^{2}=0.19\right)$. Further analyses were carried out on the eight subscales of the MAIA. Noticing and Emotional Awareness of the MAIA scale were both positively predicted by the emotional consciousness factor identified previously through PCA $\left(\beta=0.623 \pm 0.21, P<0.006 ; R^{2}=0.34, R_{\text {Adj }}^{2}=\right.$ 0.18 , and $\beta=0.701 \pm 0.19, P<0.001 ; R^{2}=0.47, R_{\text {Adj }}^{2}=0.35$, respectively), while this same factor only marginally predicted Attention Regulation $\left(\beta=0.446 \pm 0.22, P<0.054 ; R^{2}=0.52\right.$, $\left.R_{\text {Adj }}^{2}=0.27\right)$, Self-regulation $(\beta=0.461 \pm 0.23, P<0.059$; $\left.R^{2}=0.43, R_{\text {Adj }}^{2}=0.19\right)$ and Body Listening $(\beta=0.441 \pm 0.22$, $\left.P<0.057 ; R^{2}=0.52, R_{\text {Adj }}^{2}=0.27\right)$. Interestingly, Not-Worrying

Table $5 \beta$ coefficients ( + I standard error of the mean) resulting from multiple regression analyses carried out on measures of interoceptive accuracy and interoceptive awareness.

\begin{tabular}{|c|c|c|c|}
\hline \multirow[t]{2}{*}{ Predictive variable } & \multicolumn{2}{|c|}{ Interoceptive accuracy } & \multirow{2}{*}{$\begin{array}{l}\text { Interoceptive awareness } \\
\text { Confidence/accuracy } \\
\text { covariance }\end{array}$} \\
\hline & HBscore & $\begin{array}{l}\text { Recording/response } \\
\text { covariance }\end{array}$ & \\
\hline \multicolumn{4}{|l|}{ Demographics } \\
\hline Group & $0.759(0.29)^{*}$ & $0.825(0.27)^{*}$ & $0.273(0.30)$ \\
\hline Age & $-0.163(0.19)$ & $-0.24(0.17)$ & $-0.004(0.19)$ \\
\hline \multicolumn{4}{|l|}{ Physiology } \\
\hline Body mass index & $0.352(0.19)$ & $0.294(0.18)$ & $-0.037(0.20)$ \\
\hline Resting heart rate & $-0.156(0.25)$ & $-0.187(0.23)$ & $-0.415(0.25)$ \\
\hline \multicolumn{4}{|c|}{ Factors underlying self-reported instruments } \\
\hline Anxiety & $0.179(0.18)$ & $0.116(0.16)$ & $-0.136(0.18)$ \\
\hline Emotional consciousness & $0.315(0.20)$ & $0.198(0.18)$ & $0.219(0.20)$ \\
\hline Pain-related affect and reactions & $-0.627(0.30)^{*}$ & $-0.674(0.28)^{*}$ & $-0.443(0.31)$ \\
\hline \multicolumn{4}{|l|}{ Auditory attention } \\
\hline Accuracy & $-0.051(0.26)$ & & \\
\hline Stimulus/response covariance & & $0.178(0.24)$ & $0.139(0.27)$ \\
\hline
\end{tabular}

Note: *Significant predictive relation.

Abbreviation: Hbscore, heartbeat perception score. 
was negatively predicted by pain-related affect and reaction $\left(\beta=-0.641 \pm 0.27, P<0.025 ; R^{2}=0.45, R_{\text {Adj }}^{2}=0.32\right)$. Finally, Not-Distracting and Trusting were not predicted by any variable. None of the above-mentioned significant effects interacted with group (Table 6).

\section{Discussion}

The first aim of the current study was to investigate in a single sample of FM patients the three dimensions of interoception. ${ }^{45}$ First, our results showed no difference between FM patients and controls, whatever the dimension, like in some recent studies, ${ }^{16,20}$ whereas in other studies, a difference was observed. ${ }^{7,17}$ This could probably be attributed not only to different definitions and theoretical frameworks used by the authors of these studies but also to differences in sample characteristics and methodology as well as the assessment of different and unrelated dimensions of interoception. ${ }^{18}$ Nevertheless, by conducting correlation and regression analyses, we examined more precisely the relationship between interoception and affect and mood, hypervigilant self-awareness and pain, which was our second aim. Actually, pain, ${ }^{18}$ emotions and affect ${ }^{1,46}$ and anxiety ${ }^{47}$ are the key factors related to FM but also to interoception. The interest of these analyses is that the different dimensions of interoception seem to be determined by these factors. We discuss these results as follows.

\section{IA in FM}

Corroborating the findings of Rost et $\mathrm{al}^{13}$ and ValenzuelaMoguillansky et al ${ }^{16}$ we observed no difference between FM and controls in the heartbeat detection task. ${ }^{14}$ However, when considering this measure as a function of individual characteristics, performance in an exteroceptive auditory attention task and three components extracted through the self-reported questionnaires, we found that IA was explained concomitantly by group and by pain-related affect and reactions. This last component is determined by depressive symptoms, pain, affective aspects of pain and pain catastrophizing, as well as somatosensory amplification. Interestingly, group had a positive predictive value, whereas the latter had a negative predictive value. This means that increased pain-related affect and reactions in FM decrease IA. These observations were confirmed when analyzing the results of each group separately. Pain-related affect and reactions predicted IA only in patients with FM. This finding was extended since emotional consciousness was found to be a supplementary predictor of IA, suggesting a combination of pain and emotion. Such a finding tallies well with the observation of Duschek et $\mathrm{a}^{17}$ who found that IA correlated negatively with a questionnaire

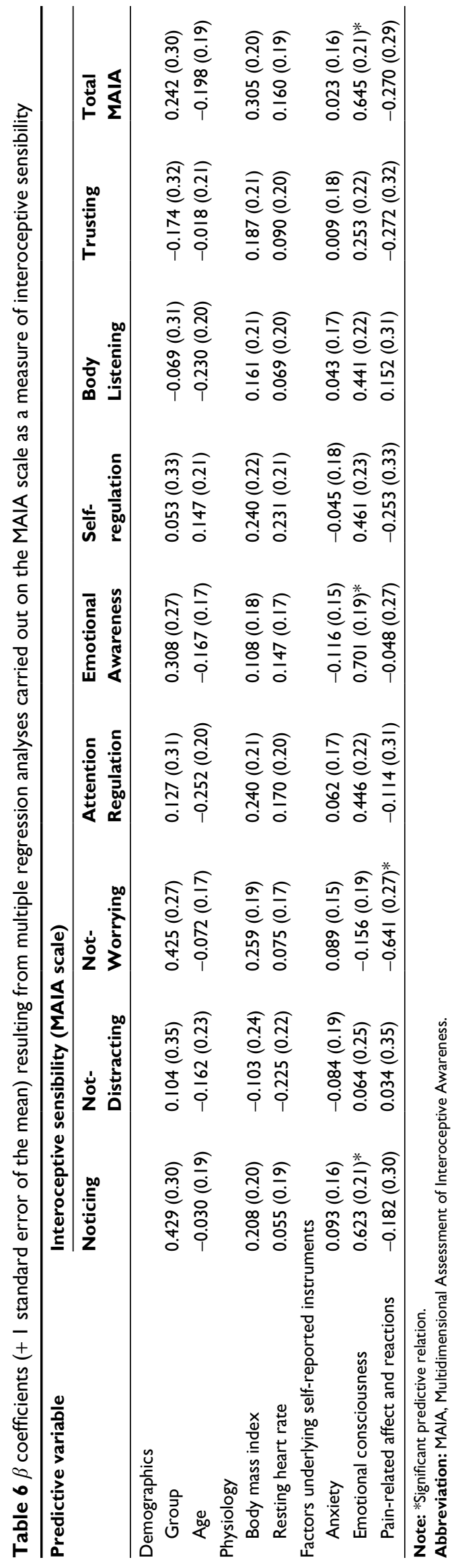


of clinical symptoms including pain and emotional wellbeing, the Fibromyalgia Impact Questionnaire. Similarly, in a study having used the paradigm of SPSs to assess interoception in $\mathrm{FM},{ }^{7}$ it was found that measures of perceptual, sensory and affective aspects of pain (two of them being the same as here and entering the pain-related affect and reactions, ie, PCS and QDSA) explained as much as $28 \%$ of variance of the parameters of SPSs. Even though the SPS paradigm does not exclusively measure aspects of interoception (just like the heartbeat detection task does not measure solely IA), this finding is quite consistent with the idea that pain is closely related to interoception ${ }^{18}$ and constitutes, along with catastrophizing and amplified somatosensory perception, a hallmark of dysfunction in FM. As predicted by McDermid et al, ${ }^{4} \mathrm{FM}$ patients may be as hypervigilant toward some forms of stimuli (such as SPSs) ${ }^{7}$ as to exteroceptive stimuli. ${ }^{16}$ In light of these results, pain and catastrophizing should therefore be investigated as concomitants or determinants of interoception, at least of IA. Interestingly, Rost et $\mathrm{al}^{13}$ did not report any significant correlation between pain catastrophizing (using the PCS) and heartbeat detection accuracy, but neither did we in the present study. This is most probably due to the fact that PCS alone captures only a limited aspect of affect and reactions related to pain, and a more composite measure like the one uncovered through the PCA might capture the whole image.

\section{IS in FM}

IS in FM was investigated in two previous studies, ${ }^{7,13}$ both having used the MAIA scale. ${ }^{48}$ Unfortunately, none of them evidenced any difference between FM and controls, and this is also the case in the present study. The absence of sensitivity of this scale with other populations ${ }^{20}$ suggests that it may not be the best tool to assess IS in chronic pain, even though its relation to emotional processes has been shown. ${ }^{9}$ Yet, despite the absence of difference between FM and controls, we found that a component we termed emotional consciousness and included self-consciousness and the intensity of emotional reactions to typical life events positively predicted the MAIA score independently from group. Further analyses showed that two subscales from the MAIA were positively predicted by this factor, namely Noticing and Emotional Awareness. Mehling et $\mathrm{al}^{48}$ defined Noticing as awareness of body sensations, being disturbing or not, and Emotional Awareness as awareness of the connection between body sensations and emotional states. These last two components closely reflect the concept of IS defined as being the dispositional tendency to be internally focused and interoceptively cognizant..$^{20,45}$
A third subscale of the MAIA, namely Not-Worrying, was negatively predicted by the pain-related affect and reactions factor. According to Mehling et al, ${ }^{20}$ Not-Worrying reflects freedom from emotional distress due to sensations of pain or discomfort. The negative relation with the pain-related affect and reactions can thus be easily understood. Still, all these predictive relations were independent from group, suggesting not only that IS, at least as assessed here, does not differ quantitatively in FM and in controls but also that its relation to pain and emotional consciousness is similar in both groups.

\section{IAW in FM}

To our knowledge, this is the only study among the rare ones that assessed interoception in $\mathrm{FM}^{13,17,26}$ to investigate the relation between heartbeat detection accuracy and confidence in responses as a measure of IAW. This is also the first one to report no difference between FM and controls. If we accept that the relationship between accuracy in a heartbeat detection task and confidence in response reflects IAW, ${ }^{20}$ then the choice of the various instruments can probably explain the absence of any effect in the present study. However, it seems difficult to choose the right instruments without a clear definition of the determinants of confidence in interoceptive judgments. A first cue is that pain intensity at the moment of testing, assessed through the VAS, is negatively correlated with IAW. Indeed, such a correlation was found for the whole sample. However, pain-related affect and reactions did not explain IAW, and no other variable did. Contrary to the pain VAS used here, the remaining measures related to pain and included in the pain-related affect and reactions factor assess more general aspects which are not time-locked. The pain VAS, just like confidence ratings in heartbeat detection accuracy, measures something that happens here-and-now, and this may be one of the dimensions of IAW our instruments failed to capture.

\section{Arousal, anxiety and interoception}

An idea that is frequently presented in the literature on interoception is that arousal and anxiety are its determinants. ${ }^{49-52}$ In the present study, RHR (which is considered as a measure of autonomous arousal) and self-report anxiety did not differ between FM patients and controls and were not predictive of any of the three dimensions of interoception. When taking a look at the published papers having used the heartbeat detection task in FM,,$^{13,17,26}$ only one reported heart variables at rest and their relationship to interoception ${ }^{13}$ and this was heartbeat variability. It was found that FM patients had a lower heartbeat variability than controls and was interpreted 
as reflecting the result of exhausted self-regulatory resources due to the persistent challenge posed by chronic pain. However, no significant association was found with IA, even though a trend toward significance and a very small effect size was described.

On the other hand, even though the relationship between anxiety and interoception seems to be widely accepted, empirical evidence suggests that this might depend on the instruments used to measure anxiety. ${ }^{50}$ Interestingly, just like us, Dunn et $\mathrm{a}^{51}$ found that anxiety, as a multidimensional construct, did not relate to IA. However, when separate dimensions of anxiety were considered, only anxiety-specific arousal was associated with interoception accuracy. Unfortunately, we did not measure different dimensions of anxiety and this might be the reason why no effect was found.

Overall, it seems that these different dimensions of anxiety might influence different dimensions of interoception, and that arousal plays an important role probably in association with anxiety. This has to be confirmed in the future, and the relationship with pain and pain-related affect explored in FM.

\section{Limitations and future directions}

It is shown that pain-related affect and reactions combined with increased emotional consciousness are related to decreased IA in FM patients. However, the present study does not allow understanding the mechanisms through which this is achieved. Another limitation is that our rather small sample was exclusively made of females, probably restricting the generalizability of the results. Correlational analyses are sensitive to the sample size, and caution is needed when interpreting the results. However, the differences between the groups were found only through regression analyses, which are more robust and reveal causal relations between predictive variables and performance. Finally, since several forms of FM have been identified, ${ }^{53}$ it seems necessary to remain cautious because the diagnostic criteria of FM are exclusively based on the symptoms and not on its pathological mechanisms. Despite these limitations, our results are in agreement with the idea that interoception in FM is modulated by pain and related affective states. They can also have a practical impact. If poor interoception contributes to an affective dysregulation and a somatosensory distortion in FM, working the perception of internal signals can be a target for therapy. This can be achieved only if the mechanisms underlying interoception in FM are better understood, and we believe that our study makes a significant contribution toward this aim.

\section{Acknowledgments}

This study benefited from funding support from the LABEX CORTEX (ANR-11-LABX-0042) of the University of Lyon, under the "Investissements d'Avenir" programme (ANR-11IDEX-0007) run by the French National Research Agency (ANR). Additionally, the authors thank the teams of the Pain Centre and the medical unit Visas (CHU de Saint-Etienne) for their precious help with the clinical sample. The authors also specifically thank Dr Creac'h and Dr Hupin who referred us the patients.

\section{Disclosure}

The authors report no conflicts of interest in this work.

\section{References}

1. Wiens S. Interoception in emotional experience. Curr Opin Neurol. 2005;18(4):442-447.

2. Wolfe F, Clauw DJ, Fitzcharles MA, et al. Fibromyalgia criteria and severity scales for clinical and epidemiological studies: a modification of the ACR preliminary diagnostic criteria for fibromyalgia. J Rheumatol. 2011;38(6):1113-1122.

3. Hollins M, Harper D, Gallagher S, et al. Perceived intensity and unpleasantness of cutaneous and auditory stimuli: an evaluation of the generalized hypervigilance hypothesis. Pain. 2009;141(3):215-221.

4. McDermid AJ, Rollman GB, McCain GA. Generalized hypervigilance in fibromyalgia: evidence of perceptual amplification. Pain. 1996;66(2-3):133-144.

5. Geisser ME, Casey KL, Brucksch CB, Ribbens CM, Appleton BB, Crofford LJ. Perception of noxious and innocuous heat stimulation among healthy women and women with fibromyalgia: association with mood, somatic focus, and catastrophizing. Pain. 2003;102(3):243-250.

6. Peters ML, Vlaeyen JW, van Drunen C. Do fibromyalgia patients display hypervigilance for innocuous somatosensory stimuli? Application of a body scanning reaction time paradigm. Pain. 2000;86(3):283-292.

7. Borg C, Emond FC, Colson D, Laurent B, Michael GA. Attentional focus on subjective interoceptive experience in patients with fibromyalgia. Brain Cogn. 2015;101:35-43.

8. Yoris A, Esteves S, Couto B, et al. The roles of interoceptive sensitivity and metacognitive interoception in panic. Behav Brain Funct. 2015;11:14.

9. Cali G, Ambrosini E, Picconi L, Mehling WE, Committeri G. Investigating the relationship between interoceptive accuracy, interoceptive awareness, and emotional susceptibility. Front Psychol. 2015;6:1202.

10. Farb N, Daubenmier J, Price CJ, et al. Interoception contemplative practice, and health. Front Psychol. 2015;6:763.

11. Matthias E, Schandry R, Duschek S, Pollatos O. On the relationship between interoceptive awareness and the attentional processing of visual stimuli. Int J Psychophysiol. 2009;72(2):154-159.

12. Critchley HD, Wiens S, Rotshtein P, Ohman A, Dolan RJ. Neural systems supporting interoceptive awareness. Nat Neurosci. 2004;7(2):189-195.

13. Rost S, Van Ryckeghem DM, Schulz A, Crombez G, Vögele C. Generalized hypervigilance in fibromyalgia: normal interoceptive accuracy, but reduced self-regulatory capacity. J Psychosom Res. 2017;93:48-54.

14. Schandry R. Heart beat perception and emotional experience. Psychophysiology. 1981;18(4):483-488.

15. Schandry R, Bestler M. The association between parameters of cardiovascular functioning and heartbeat perception. In: Vaitl D, Schandry R, editors. From the Heart to the Brain: The Psychophysiology of Circulation-Brain Interaction. Frankfurt am Main: Peter Lang; 1995:223-250.

16. Valenzuela-Moguillansky C, Reyes-Reyes A, Gaete MI. Exteroceptive and interoceptive body-self awareness in fibromyalgia patients. Front Hum Neurosci. 2017;11:117. 
17. Duschek S, Montoro CI, Reyes Del Paso GA. Diminished interoceptive awareness in fibromyalgia syndrome. Behav Med. 2017;43(2):100-107.

18. Di Lernia D, Serino S, Riva G. Pain in the body. Altered interoception in chronic pain conditions: a systematic review. Neurosci Biobehav Rev. 2016;71:328-341.

19. Barsky AJ, Goodson JD, Lane RS, Cleary PD. The amplification of somatic symptoms. Psychosom Med. 1988;50(5):510-519.

20. Mehling WE, Daubenmier J, Price CJ, Acree M, Bartmess E, Stewart AL. Self-reported interoceptive awareness in primary care patients with past or current low back pain. J Pain Res. 2013;6:403-418.

21. Garfinkel SN, Seth AK, Barrett AB, Suzuki K, Critchley HD. Knowing your own heart: distinguishing interoceptive accuracy from interoceptive awareness. Biol Psychol. 2015;104:65-74.

22. Mor N, Winquist J. Self-focused attention and negative affect: a metaanalysis. Psychol Bull. 2002;128(4):638-662.

23. Pollatos O, Kirsch W, Schandry R. On the relationship between interoceptive awareness, emotional experience, and brain processes. Brain Res Cogn Brain Res. 2005;25(3):948-962.

24. Werner NS, Duschek S, Mattern M, Schandry R. Interoceptive sensitivity modulates anxiety during public speaking. J Psychophysiol. 2009;23:85-94.

25. Craig AD. Interoception: the sense of the physiological condition of the body. Curr Opin Neurobiol. 2003;13(4):500-505.

26. Kupers RC, Gybels JM, Gjedde A. Positron emission tomography study of a chronic pain patient successfully treated with somatosensory thalamic stimulation. Pain. 2000;87(3):295-302.

27. Pichot $\mathrm{V}$, Roche F, Celle $\mathrm{S}$, Barthélémy JC, Chouchou F. HRV analysis: a free software for analyzing cardiac autonomic activity. Front Physiol. 2016;7:557.

28. Michael GA, Naveteur J, Dupuy MA, Jacquot L. My heart is in my hands: the interoceptive nature of the spontaneous sensations felt on the hands. Physiol Behav. 2015;143:113-120.

29. Pollatos O, Schandry R. Accuracy of heartbeat perception is reflected in the amplitude of the heartbeat-evoked brain potential. Psychophysiology. 2004;41(3):476-482.

30. Michael GA, Magnin C, Hamon J, et al. Adaptation Française de la Multidimensional Assessment of Interoceptive Awareness (fMAIA) [French Adaptation of the Multidimensional Assessment of Interoceptive Awareness (fMAIA)]. Paper presented at: $56^{\text {eme }}$ Congrès de la Société Française de Psychologie; September 7-9, 2016; Strasbourg. French.

31. Spielberger CD, Gorsuch RL, Lushene R, Vagg PR, Jacobs GA. Manual for the State-Trait Anxiety Inventory. Palo Alto: Consulting Psychologists Press. 1983.

32. Beck AT, Ward CH, Mendelson M, Mock J, Erbaugh J. An inventory for measuring depression. Arch Gen Psychiatry. 1961;4:561-571.

33. Collet L, Cottraux J. Inventaire abrégé de la dépression de Beck (13 items). Étude de la validité concurrente avec les échelles de Hamilton et de ralentissement de Wildlöcher [The shortened Beck depression inventory (13 items). Study of the concurrent validity with the Hamilton scale and Widlöcher's retardation scale]. Encephale. 1986;12(2):77-79. French [with English abstract].

34. Larsen RJ. Theory and measurement of affect intensity as an individual difference characteristic. Diss Abstr Int. 1984;85:2297B.

35. Onnein-Bonnefoy C. Le rôle de l'affectif dans le processus de persuasion publicitaire: la formation des attitudes lors de l'exposition à une publicité émotionnelle pour une marque inconnue [The role of emotion in the process of advertising persuasion: the formation of attitudes when exposed to an emotional advertisement for an unknown brand] [doctoral thesis]. Paris: Paris Dauphine University; 1999. French.
36. Naveteur J, Antoine P, Charron C. Santé et vieillissement: Effet de l'âge et des douleurs sur l'amplification somatosensorielle [Health and aging: effect of age and pain on somatosensory amplification]. Paper presented at: 7th Congress of the Association Francophone de Psychologie de la Santé; December 17-19, 2012; Lille. French.

37. Fenigstein A, Scheier MF, Buss AH. Public and private self-consciousness: assessment and theory. J Consult Clin Psychol. 1975;43:522-527.

38. Rimé B, Le Bon C. Le concept de conscience de soi et ses opérationnalisations [The concept of self-awareness and its operationalizations]. L'Année Psychologique. 1984;84(4):535-553. French [with English abstract].

39. French DJ, Noël M, Vigneau F, French JA, Cyr CP, Evans RT. L'Échelle de dramatisation face à la douleur PCS-CF: adaptation canadienne en langue française de l'échelle Pain Catastrophizing Scale. [PCS-CF: a French language, French-Canadian adaptation of the Pain Catastrophizing Scale]. Can J Behav Sci. 2005;37(3):181-192. French [with English abstract].

40. Sullivan MJL, Bishop SR, Pivik J. The pain catastrophizing scale: development and validation. Psychol Assessment. 1995;7(4):524-532.

41. Boureau F, Luu M, Doubrère JF, Gay C. Élaboration d'un questionnaire d'auto-évaluation de la douleur par liste de qualificatifs: Comparaison avec le McGill pain questionnaire de Melzack [Elaboration of a questionnaire of self-evaluation of pain by list of qualifiers: comparison with the McGill pain questionnaire of Melzack]. Thérapie. 1984;39:119-129. French [with English abstract].

42. Buldeo N. Interoception: a measure of embodiment or attention? Int Body Psychother J. 2015;14(1):65-79.

43. Welch BL. The generalisation of "Student's" problems when several different population variances are involved. Biometrika. 1947;34(1-2):28-35.

44. Cameron OG. Visceral Sensory Neuroscience: Interoception. Oxford: Oxford University Press; 2002.

45. Garfinkel SN, Critchley HD. Interoception, emotion and brain: new insights link internal physiology to social behaviour. Commentary on: "Anterior insular cortex mediates bodily sensibility and social anxiety" by Terasawa et al. (2012). Soc Cogn Affect Neurosci. 2013;8(3):231-234.

46. Critchley HD, Garfinkel SN. Interoception and emotion. Curr Opin Psychol. 2017;17:7-14.

47. Paulus MP, Stein MB. Interoception in anxiety and depression. Brain Struct Funct. 2010;214(5-6):451-463.

48. Mehling WE, Price C, Daubenmier JJ, Acree M, Bartmess E, Stewart A. The Multidimensional Assessment of Interoceptive Awareness (MAIA). PLoS One. 2012;7(11):e48230.

49. Cameron OG. Interoception: the inside story-a model for psychosomatic processes. Psychosom Med. 2001;63(5):697-710.

50. Domschke K, Stevens S, Pfleiderer B, Gerlach AL. Interoceptive sensitivity in anxiety and anxiety disorders: an overview and integration of neurobiological findings. Clin Psychol Rev. 2010;30(1):1-11.

51. Dunn BD, Galton HC, Morgan R, et al. Listening to your heart. How interoception shapes emotion experience and intuitive decision making. Psychol Sci. 2010;21(12):1835-1844.

52. Pollatos O, Herbert BM, Matthias E, Schandry R. Heart rate response after emotional picture presentation is modulated by interoceptive awareness. Int J Psychophysiol. 2007;63(1):117-124.

53. Arnold LM, Choy E, Clauw DJ, et al. Fibromyalgia and chronic pain syndromes: a white paper detailing current challenges in the field. Clin J Pain. 2016;32(9):737-746 
The Journal of Pain Research is an international, peer reviewed, open access, online journal that welcomes laboratory and clinical findings in the fields of pain research and the prevention and management of pain. Original research, reviews, symposium reports, hypothesis formation and commentaries are all considered for publication
The manuscript management system is completely online and includes a very quick and fair peer-review system, which is all easy to use. Visit http://www.dovepress.com/testimonials.php to read real quotes from published authors.

Submit your manuscript here: https://www.dovepress.com/journal-of-pain-research-journal 